margin(anal side). Another endoclip was placed over the existing line on the opposite colonic wall distally creating a pulley traction system.

Results Three colonic ESD cases were carried out. Site of lesions were rectum $(3.7 \times 3.0 \mathrm{~cm})$, ascending colon $(4.0 \times 3.5$ $\mathrm{cm})$ and distal sigmoid colon $(1.8 \times 1.5 \mathrm{~cm})$. Average completing time was 169.3 minutes. There were no perforation in all cases performed. Enbloc resection was achieved in all cases. Conclusions The modified pulley traction system was helpful in achieving en bloc resection, especially at difficult locations. This method provides an alternative where similar devices or accessories are limited outside Japan, whereas dental floss and endoclips are readily available throughout the world.

\section{IDDF2019-ABS-0304 GASTROESOPHAGEAL REFLUX DISEASE AND CHRONIC GRAFT FAILURE IN LUNG TRANSPLANTATION: KEEP THE TARGET IN SIGHT}

${ }^{123}$ Guohui Jiao*. 'Jiangsu Key Laboratory of Organ Transplantation, China; ${ }^{2}$ Tianjin Institute of Digestive Disease, China; ${ }^{3}$ Law School of Peking University, China

\subsection{6/gutjnl-2019-IDDFabstracts.226}

Background Gastroesophageal reflux disease (GERD) has been reported in up to $88 \%$ of patients after lung transplantation (LTx). Concern has been raised on the aspiration of refluxate which contributed to the nonalloimmune cause for the development of chronic lung allograft failure (CLAD), such as bronchiolitis obliterans syndrome (BOS). This study included a comprehensive review of the current literature on the association of CLAD/BOS and GERD by discussing the pathophysiology, evaluation, and management of GERD.

Methods Patient data included age, sex, body mass index, donor and recipient cytomegalovirus immune status, indication for LTx, clinical test data, LTx date, intraoperative data, postLTx medication, post-LTx complications, including acute rejection, CLAD occurrence, and death and anti-reflux therapy were recorded.

Results Publications from PubMed, Scopus and Web of Science on "lung transplantation, gastroesophageal reflux" were reviewed and analyzed. Cases from our center were reviewed and summarized.

Common associations of reflux and transplanted lung status were illustrated by: hazard ratio of reflux on time to development of BOS, effect of reflux on FEV1, relationship between prevalence and extent of GERD and types of transplant; association between the prevalence and type of reflux and gastric aspiration in patients with and without BOS; quantification of reflux, aspiration, and allograft injury. Post-lung transplant exposure to persistent PPI therapy had a beneficial effect. Exposure to severe acid reflux pretransplant was associated with early readmission following lung transplantation in need of aggressive early antireflux therapy. For pediatric recipients, gastric dysmotility related to allograft dysfunction.

Bronchoalveolar lavage fluid (BALF) is another useful tool for the current study in LTx patients. There have been shown relationships of levels of bile acids, IL-8, neutrophils on the development of BOS; aspiration on immune mediator concentrations related to $\mathrm{BOS}$; acid exposure, volume exposure, or reflux events correlated to and neutrophilia, bile acids and other dysregulation of immune mediator concentrations; the level of pepsin related to acute rejection.
Conclusions Our review of the literature and preliminary data supports that GERD related to lung allograft injury and longterm failure, encouraging a strategy of early diagnosis and aggressive reflux management, aiming to prolong the duration of normal graft function.

\section{IDDF2019-ABS-0309 GASTRO-INTESTINAL ULCERATIONS/ STRICTURES IN OPIOID ABUSERS}

Pulkit Dhiman*, Arshdeep Singh, Vandana Midha, Ramit Mahajan, Varun Mehta, Yogesh Gupta, Ajit Sood. Dayanand Medical College and Hospital, Ludhiana, India

\subsection{6/gutjnl-2019-IDDFabstracts.227}

Background Opioid-induced bowel dysfunction include constipation, gastro-oesophageal reflux, abdominal distension and intestinal pseudo-obstruction. We report patients presenting with gastro-intestinal strictures and ulcers secondary to opioid abuse, an entity not well described in the literature.

\section{Abstract IDDF2019-ABS-0309 Table 1}

\begin{tabular}{|c|c|}
\hline \multicolumn{2}{|l|}{$(n=18)$} \\
\hline Mean Age ( \pm Standard Deviation) (Years) & $38.46 \pm 14.86$ \\
\hline Males (N) (\%) & $18(100)$ \\
\hline \multicolumn{2}{|l|}{ Clinical Presentation } \\
\hline Pain Abdomen (N)(\%) & $10(55.55)$ \\
\hline Vomiting $(\mathrm{N})(\%)$ & $11(61.11)$ \\
\hline Loss Of Weight $(\mathrm{N})(\%)$ & $10(55.55)$ \\
\hline Loss Of Appetite (N)(\%) & $3(16.66)$ \\
\hline Fatigue $(\mathrm{N})(\%)$ & $14(77.78)$ \\
\hline Anemia (Hemoglobin <10 g\%) (N)(\%) & $16(88.89)$ \\
\hline Gastric Outlet Obstruction (N)(\%) & $9(50.0)$ \\
\hline Small Bowel Obstruction (N)(\%) & $5(27.78)$ \\
\hline GI Bleed (N)(\%) & $5(27.78)$ \\
\hline Mean Weight Loss ( \pm Standard Deviation) $(\mathrm{Kg})$ & $22.85 \pm 9.06$ \\
\hline Co-Addictions & $3(16.66)$ \\
\hline Alcohol $(\mathrm{N})(\%)$ & - \\
\hline \multicolumn{2}{|l|}{ Tobacco (N)(\%) } \\
\hline Co-Infections (N)(\%) & $2(11.11) /-/-$ \\
\hline \multicolumn{2}{|l|}{$\mathrm{HCV} / \mathrm{HBV} / \mathrm{HIV}$} \\
\hline Mean Opium Consumption ( \pm Standard Deviation) Kg/month & $1.46 \pm 0.43$ \\
\hline Mean Duration of Opioid Addiction ( \pm Standard Deviation)(Years) & $4.69 \pm 6.09$ \\
\hline Mean Duration of Symptoms ( \pm Standard Deviation)(Days) & $222.07 \pm 392.93$ \\
\hline \multicolumn{2}{|l|}{ Endoscopic Findings } \\
\hline Ulcers $(\mathrm{N})(\%)$ & $4(22.22)$ \\
\hline Esophageal $(\mathrm{N})(\%)$ & - \\
\hline Gastro-Duodenal (N)(\%) & $2(11.11)$ \\
\hline Jejuno-lleal $(\mathrm{N})(\%)$ & $2(11.11)$ \\
\hline Colonic (N)(\%) & - \\
\hline Strictures $(\mathrm{N})(\%)$ & 14 (77.78) \\
\hline Esophageal $(\mathrm{N})(\%)$ & - \\
\hline Gastro-Duodenal (N)(\%) & $9(50.00)$ \\
\hline Jejuno-lleal $(\mathrm{N})(\%)$ & $5(27.78)$ \\
\hline Colonic (N)(\%) & - \\
\hline \multicolumn{2}{|l|}{ Treatment } \\
\hline Balloon Dilatation $(\mathrm{N})(\%)$ & $10(55.55)$ \\
\hline Mean Number Of Dilatation Sessions ( \pm Standard Deviation) (N) & $1.57 \pm 0.78$ \\
\hline Failed Balloon Dilatation (N)(\%) & $6(33.33)$ \\
\hline Surgery $(N)(\%)$ & $8(44.44)$ \\
\hline
\end{tabular}

